\title{
Development of a model for particulate matter pollution in Australia with implications for other satellite-based models
}

Gavin Pereira ${ }^{\mathrm{a}}$, Hyung Joo Lee ${ }^{\mathrm{b}}$, Michelle Bell $^{\mathrm{c}}$, Annette Regan ${ }^{\mathrm{a}}$, Eva Malacova ${ }^{\mathrm{a}}$, Ben Mullins ${ }^{\mathrm{a}}$, Luke Knibbs ${ }^{\mathrm{d}}$

a. School of Public Health, Curtin University, WA Australia

b. NASA Ames Research Center, California USA.

c. School of Forestry and Environmental Studies, Yale University, CT USA

d. School of Population Health, University of Queensland, Qld Australia

Corresponding author: Gavin Pereira

Address: School of Public Health, Curtin University, GPO Box U1987, Perth, Western Australia 6845, Australia

Email: gavin.f.pereira@curtin.edu.au

\section{Acknowledgements}

Dr Pereira is supported by NHMRC Early Career Fellowship (Sidney Sax) \#1052236 and project grant \#1099655. Dr Lee was supported by an appointment to the NASA Postdoctoral Program at the Ames Research Center, administered by Oak Ridge Associated Universities through a contract with NASA. Dr Knibbs acknowledges an NHMRC Early Career (Australian Public Health) Fellowship (APP1036620). Professor Bell would like to acknowledge the funding source National Institutes of Health (NIEHS R01ES019587). A special thanks is extended to John George for producing a map of the $\mathrm{PM}_{10}$ monitoring sites, provided in the Supplementary Material.

\section{Keywords}

Particulate matter; satellite remote sensing; air pollution; land use regression; aerosol optical depth 


\title{
Development of a model for particulate matter pollution in Australia with implications for other satellite-based models
}

\begin{abstract}
Estimating exposure to particulate matter $\left(\mathrm{PM}_{10}\right)$ air pollution concentrations in Australia is challenging due to relatively few monitoring sites relative to the geographic distribution of the population. We modelled daily ground-level $\mathrm{PM}_{10}$ concentrations for the period 2006-2011 for Australia using linear mixed models with satellite remote-sensed AOD, land-use and geographical variables as predictors. The variation in daily $\mathrm{PM}_{10}$ explained by the model was $51 \%$ for Australia overall, and ranged from $51 \%$ for Tasmania to $78 \%$ for South Australia. Cross-validation indicated that the models were most suitable for prediction in New South Wales and Victoria and least suitable for prediction in Western Australia, the Australian Capital Territory and Tasmania. Most of the variation in $\mathrm{PM}_{10}$ concentrations was explained by temporal rather than spatial variation. The inclusion of AOD and other predictors did not substantially improve model performance. Temporal models were sufficient to account for daily $\mathrm{PM}_{10}$ variation recorded by statutory monitors.
\end{abstract}

Key words: particulate matter; $\mathrm{PM}_{10}$; $\mathrm{AOD}$; air pollution; land-use regression.

\section{Introduction}

Particulate matter (PM) air pollution is a major air quality issue ${ }^{1}$. In Australia, it is estimated that more than 3000 people die prematurely each year as a result of air pollution ${ }^{2}$. Studies have linked both $\mathrm{PM}_{10}(<10 \mu \mathrm{m}$ aerodynamic diameter $)$ and $\mathrm{PM}_{2.5}(<2.5 \mu \mathrm{m}$ aerodynamic diameter $)$ with a range of health problems including respiratory and cardiovascular morbidity ${ }^{3-5}$, adverse perinatal outcomes ${ }^{6,7}$ and lung cancer ${ }^{8}$. Major sources of $\mathrm{PM}_{10}$ in Australia are bushfires ${ }^{9}$, dust storms ${ }^{10}$, and anthropogenic combustion emissions ${ }^{11}$, which vary both geographically and seasonally. To ascertain exposure, health studies generally require wide geographical coverage at sufficient temporal resolution. This underscores the need for a spatiotemporal model with a daily resolution to estimate exposure to $\mathrm{PM}_{10}$. 
A challenge in estimating exposure to ambient particulate matter is that in some countries, such as Australia, there are few regulatory ground monitoring sites relative to the geographic distribution of the population ${ }^{12}$, which introduces considerable sample loss when populations who do not live close to a monitor are excluded to minimize exposure misclassification ${ }^{13}$. This challenge can been addressed by use of land-use regression (LUR) ${ }^{14}$ that first uses geographically varying predictors (e.g., proximity to major roads) to fit the model with measured pollutant concentrations, and next applies that model at unmonitored locations ${ }^{15}$. The relatively recent addition of satellite remote sensing measurements of Aerosol Optical Depth (AOD) as a predictor to these models ${ }^{16}$ has led to a putative improvement in their geographic accuracy. Consequently, models for PM air pollution covering large geographic regions have been developed for countries including the United States ${ }^{17}$, Canada ${ }^{18}$ and China ${ }^{19}$.

However, substantial uncertainties remain. Firstly, it is unclear as to whether equally reliable estimates can be obtained in settings with relatively lower concentrations due to the lower signal-tonoise ratio. Moreover, the improvement in models for daily $\mathrm{PM}_{10}$ attributable to satellite remotesensed AOD has not been quantified. It is also unknown as to the extent to which transient air pollution events (e.g., bushfire or dust storm events) affect the validity of these models. In this situation it is plausible that such events might inflate the proportion of variation explained by model (i.e. high $\mathrm{R}^{2}$ ) yet the model might not fit the non-event periods. Finally, there is no such model for daily $\mathrm{PM}_{10}$ in Australia.

In this study, we developed state-specific models for daily ground-level $\mathrm{PM}_{10}$ concentrations using satellite remote-sensed AOD and other geographic predictors for the period 2006-2011 in Australia, a country with relatively lower pollution levels. We investigated the influence of major air pollution events on model performance. We also quantified the value of including satellite remote-sensed AOD relative to more parsimonious models. 


\section{Methods}

\subsection{Data Sources}

\subsubsection{Ground-monitored $\mathrm{PM}_{10}$}

$\mathrm{PM}_{10}$ in Australia is measured daily (average 24 hour concentrations), in contrast with the United States and many other countries where it is measured every three to six days ${ }^{20}$. We obtained, from each state's Environmental Protection Authority (EPA), daily ground-level $\mathrm{PM}_{10}$ measurements from 1st January 2006 to 31st December 2011 (2191 days) from 75 monitoring sites across Australia (Table 1 and Supplementary Figure $1 \mathrm{a}-\mathrm{b})$. The $\mathrm{PM}_{10}$ monitoring sites were concentrated in and around capital cities, which are located near the coast. Continuous measurements of $\mathrm{PM}_{10}$ were obtained using Tapered Elemental Oscillating Microbalance (TEOM) monitors ${ }^{21}$. Since the TEOM heats air samples (to $50^{\circ} \mathrm{C}$ ), it can underestimate PM10 levels when particles contain semi-volatile or volatile material ${ }^{22}$. To account for this, $\mathrm{PM}_{10}$ measurements have an internal correction factor applied by the TEOM. While this method does not fully address sample loss in areas dominated by volatile particles

${ }^{23}$, it is widely-used in Australia and elsewhere for assessing compliance with regulations and in health studies. The EPA in each state runs their own quality assurance algorithms over the data before it is released. We also performed additional checks to ensure that the data values were reasonable and that there were not too many missing values, before proceeding with the analysis.

For the 75 sites over the six year period, there were $143129 \mathrm{PM}_{10}$ measurements available for analysis. The highest $\mathrm{PM}_{10}$ concentrations were recorded during the Australian Dust Storm in New South Wales and Queensland between $22^{\text {nd }}$ and $24^{\text {th }}$ September 2009 . The highest daily $\mathrm{PM}_{10}$ concentration was over $2400 \mu \mathrm{g} / \mathrm{m}^{3}$ in Newcastle, New South Wales, on $23^{\text {rd }}$ September 2009 , with an average concentration of $1080 \mu \mathrm{g} / \mathrm{m}^{3}$ across New South Wales and Queensland. 
(Table 1 here)

\subsubsection{Satellite remote-sensed Aerosol Optical Depth}

Collection 6 MODIS AOD (Level 2; $10 \mathrm{~km}$ resolution) was obtained from the National Aeronautics and Space Administration (NASA)'s Earth Observing System (EOS) satellites, Terra (launched in 2000) and Aqua (launched in 2002), over Australia for the period 2006-2011. AOD is a measure of light extinction (i.e., scattering and absorption) by aerosols in the atmospheric column, which makes the AOD data useful for particle concentration prediction. MODIS AOD data are retrieved every one or two days at a global scale but only in cloud-free conditions. The Terra and Aqua satellites cross the equator at $10.30 \mathrm{am}$ (descending orbit) and 1.30pm (ascending orbit) local sun times respectively with a scanning swath of $2330 \mathrm{~km}$ (cross track) by $10 \mathrm{~km}$ (along-track at nadir) ${ }^{20}$. Therefore, these two satellites provide the information of particle abundance at two different times, morning (Terra) and early afternoon (Aqua), indicating part of the diurnal variability in aerosol levels. Despite the difference in overpass time, same retrieval algorithms are applied to both Aqua and Terra AOD data. To have the best spatial coverage of AOD retrievals, we used AOD data products, which merged Dark Target (DT) and Deep Blue (DB) algorithms ${ }^{24-26}$. The merged AOD data are useful for a country consisting of mixed land cover (i.e. vegetation, semi-arid, and desert areas) such as Australia. Only AOD data with the quality assurance flag of 2 and 3 (scale of $0-3$ ) were selected for high data quality. More details about the DT/DB AOD data can be found in Levy et al. ${ }^{24}$, Hsu et al. ${ }^{25}$, and Sayer et al. 26.

For each $\mathrm{PM}_{10}$ site, the AOD for each day was calculated as the average of the AOD values within a $10 \mathrm{~km}$ radius of the site (based on the $10 \mathrm{~km}$ nominal resolution of MODIS). AOD values were calculated separately for Aqua and Terra for each site and day. The Aqua and Terra values had nonequivalent distributions, most likely due to diurnal patterns of aerosols and calibration issues, particularly for Terra AOD ${ }^{20}$. 


\subsubsection{Explanatory $(X)$ variables}

For each $\mathrm{PM}_{10}$ measurement site, we obtained data on geographical and land-use variables that are potentially associated with $\mathrm{PM}_{10}$ concentrations. There were 14 area-level explanatory variables calculated at 25 different circular areas (buffers), four area-level variables calculated at five buffers, and 25 point-level variables, resulting in 395 explanatory variables (Table 2).

The variables related to bushfires (annual and monthly active fire and burnt area) had five buffers with radii from $10 \mathrm{~km}$ to $250 \mathrm{~km}$ (Supplementary Table 1) to give a total of 20 buffer variables (four variables calculated at five buffers each). The land-use and geographical variables had 25 buffers from $100 \mathrm{~m}$ to $100 \mathrm{~km}$ (Supplementary Table 1) giving a total of 350 buffer variables (14 variables calculated at 25 buffers each). Buffer variables were calculated using either the sum or the average of the variable within the buffer.

The 25 point variables included meteorological, elevation and distance variables and were calculated at each monitoring point. We also included a continuous variable day to account for longer term trend (Supplementary Figure 2) and a categorical variable season (Supplementary Figure 3) with autumn (fall) as the reference group. Detailed information about the variables is contained in Supplementary Table 1.

(Table 2 here)

\subsection{Analyses}

\subsubsection{Aqua versus Terra AOD values}

Although Terra values can be used when Aqua is not available, in order to reduce missing values, this might introduce additional uncertainty due to the difference between the two satellite observations. Terra and Aqua AOD data reflect aerosol levels at two different time points (i.e., Terra in the morning 
and Aqua in the afternoon). Therefore, it may not be reasonable to use Terra AOD when Aqua AOD is not available because of the diurnal variability in aerosol levels influenced by emissions and local meteorology. The calibration issue particularly for Terra AOD can also make such an approach less appropriate. However, it is still worth testing the effect of using both Aqua and Terra AOD data on the model performance. To determine the benefit of using both the Aqua and Terra data versus Aqua only, we examined the AOD data for the state with the largest number of sites (New South Wales). There were 19981 AOD values available in New South Wales out of a possible 56966 values (one for each of the 26 sites and 2191 days). Missing AOD data are mainly caused by cloud cover. The available AOD values consisted of: (1) 8193 observations with Aqua values only, (2) 7978 observations with Terra values only, and (3) 3810 observations with both Aqua and Terra values. Analyses were performed using primarily Aqua values and Terra values when an Aqua value was not available. The results were compared to an analysis performed using only the Aqua values to determine if it was beneficial to include the Terra data.

For New South Wales, the Aqua AOD values had a mean of 0.05 (dimensionless) and a standard deviation of 0.08 , while the Terra values had a mean of 0.08 and a standard deviation of 0.08 . It was therefore necessary to transform the Terra values so that they had the same distribution (mean and standard deviation) as the Aqua values. For site $i$ and day $j$, the transformed Terra value $r_{i j}$ is given by

$$
r_{i j}=\operatorname{sd}(A) \times\left(t_{i j}-\operatorname{mean}(T)\right) / \operatorname{sd}(T)+\operatorname{mean}(A),
$$

where $t_{i j}$ is the actual Terra value, and mean $(A)$ and $\operatorname{sd}(A)$ are the mean and standard deviation respectively of all available Aqua values for New South Wales, and mean $(T)$ and $\operatorname{sd}(T)$ are the mean and standard deviation of all available Terra values for New South Wales prior to transformation.

\subsubsection{Statistical models}

We modelled the daily relationship between $\mathrm{PM}_{10}$ and AOD using a linear mixed model with fixed and random effects. For site $i$ and day $j$, the general form of the full model was 


$$
\mathrm{PM}_{i j}=\left(\beta_{0}+\beta_{1} \mathrm{AOD}_{i j}+\beta_{2} X_{2, i j}+\ldots+\beta_{p} X_{p, i j}\right)+\left(\mathrm{u}_{0 i}+\mathrm{u}_{1 i} \mathrm{AOD}_{i j}+\mathrm{v}_{0 \mathrm{j}}\right)+\varepsilon_{i j},
$$

where $\beta$ 's represent fixed intercept and slopes, $\mathrm{u}_{0 i}$ and $\mathrm{v}_{0 \mathrm{j}}$ are random intercepts and $\mathrm{u}_{1 i}$ is a random slope. The random effects were assumed to be independent and normally distributed with a mean of zero and variance-covariance matrix $\Sigma$. The errors $\varepsilon_{i j}$ are assumed to be normally and independently distributed conditional on the random effects, with a mean of zero and variance $\sigma_{\mathrm{e}}{ }^{2}$.

We constructed separate models for each state as well as a model for the entire data set (75 sites). The following models were fitted.

Model 0-Intercepts only

The reference model consists of intercepts only:

$$
\mathrm{PM}_{i j}=\beta_{0}+\mathrm{u}_{0 i}+\mathrm{v}_{0 j}+\varepsilon_{i j}
$$

Model 1-Temporal model

Model 1 consists of fixed effects for day and season plus random intercepts for site and day:

$$
\mathrm{PM}_{i j}=\beta_{0}+\beta_{1} \mathrm{day}_{\mathrm{j}}+\beta_{2} \text { season }_{\mathrm{j}}+\mathrm{u}_{0 i}+\mathrm{v}_{0 j}+\varepsilon_{i j}
$$

Model 2 - Temporal model with AOD

Model 2 consists of Model 1 above plus an additional covariate, AOD:

$$
\mathrm{PM}_{i j}=\beta_{0}+\beta_{1} \mathrm{day}_{j}+\beta_{2} \operatorname{season}_{j}+\beta_{3} \mathrm{AOD}_{i j}+\mathrm{u}_{0 i}+\mathrm{v}_{0 j}+\varepsilon_{i j} .
$$

Model 3 - Temporal model with site-varying AOD effect 
Model 3 consists of Model 2 above plus a random slope on $A O D$ for each site:

$$
\mathrm{PM}_{i j}=\beta_{0}+\beta_{1} \mathrm{day}_{j}+\beta_{2} \operatorname{season}_{j}+\beta_{3} \mathrm{AOD}_{i j}+\mathrm{u}_{0 i}+\mathrm{v}_{0 j}+\mathrm{u}_{1 i} \mathrm{AOD}_{i j}+\varepsilon_{i j}
$$

Model 4 - Spatiotemporal model with site-varying AOD effect

Model 4 consists of Model 3 above plus explanatory variables ( $X$ variables).

For each model, we calculated $\mathrm{R}^{2}$, root-mean-square-error (RMSE), BIC as well as estimates of the variance components ( $\%$ of total variation) for the random effects. The following $\mathrm{R}^{2}$ values ${ }^{27,28}$ were calculated:

(1) pseudo $R$-squared $\left(R^{2}\right)$ - the squared correlation between the fitted and observed values,

(2) marginal $R$-squared $\left(R_{m}^{2}\right)$ - the proportion of the variance explained by the fixed effects alone, and

(3) conditional $R$-squared $\left(R_{c}^{2}\right)$ - the proportion of the variance explained by both the fixed and random effects.

Although the pseudo R-squared is the most commonly used, marginal and conditional $\mathrm{R}^{2}$ values are useful measures for evaluating the contributions of the fixed and random effects ${ }^{27}$. These were obtained using the $R$ package MuMIn and the command r.squaredGLMM(). All analyses were performed using $R$ software.

\subsubsection{Variable selection}

The $\mathrm{X}$ variables were selected using a three stage process as follows. In the first stage, each of the $395 \mathrm{X}$ variables were individually regressed against $\mathrm{PM}_{10}$ using the equation below.

$$
\mathrm{PM}_{i j}=\beta_{0}+\beta_{1} \mathrm{day}_{j}+\beta_{2} \operatorname{season}_{j}+\beta_{3} X_{k, i j}+\mathrm{u}_{0 i}+\mathrm{v}_{0 j}+\varepsilon_{i j}, \quad k=1, \ldots, 395 .
$$


This equation is equivalent to model 1 with an $\mathrm{X}$ variable included. For each $\mathrm{X}$ variable, we obtained an estimate of the regression coefficient $\beta_{3}$, its p-value and the AIC for the model. A variable was a candidate for selection if: (1) $p<0.05$ and, (2) AIC was less than that of Model 1 (the equivalent model without the $\mathrm{X}$ variable). This ensured that the variables selected were significant predictors of $\mathrm{PM}_{10}$ and that their inclusion improved the fit of the model. The variables remaining were then used in the second stage of selection.

In the second stage, we identified variables with the same characteristics but different measurement periods, for example annual average active fire $20 \mathrm{~km}$ and monthly active fire $20 \mathrm{~km}$, and eliminated the variable with the longer averaging period. For buffer variables that were highly correlated, for example major roads $300 \mathrm{~m}$ and major roads $400 \mathrm{~m}$, we selected the variable that provided the best fit (lowest AIC value). The variables remaining after this process were used in the third stage of variable selection.

The third stage involved selecting the final set of predictors from the variables in stage two. Standard methods of variable selection suffer from several drawbacks. Subset selection methods, such as stepwise selection, are convenient but their results can be highly variable ${ }^{29}$. We used the lasso method ${ }^{29}$, a regression shrinkage and selection approach that combines the favorable aspects of subset selection and ridge regression. Lasso can select smaller models containing the most important predictors with a higher prediction accuracy when there is a large number of predictors that have small to moderate sized effects ${ }^{29}$. For each lasso iteration, corresponding to values of the shrinkage parameter $(\lambda)$, we calculated the model's RMSE. The final set of X variables was obtained from the lasso iteration that produced the lowest model RMSE provided that all the X variables in the model were significant (Satterthwaite approximation, $\mathrm{p}<0.05$ ).

\subsection{Validation}


We performed leave-one-out cross-validation (LOOCV) to evaluate the performance of the spatiotemporal model (Model 4) for each region. We used LOOCV since Tasmania and the Australian Capital Territory had only two sites and few observations, thus requiring as many samples as possible in the training set. First, we separated the data for one observation (the test observation) and fitted the model using the remaining $n-1$ observations. The model was then used to predict the $\mathrm{PM}_{10}$ concentration for the test observation. This process was repeated for all $n$ observations. For each test observation, the error was defined as the difference between the measured and predicted $\mathrm{PM}_{10}$ values. We calculated the root-mean-square-error (CV RMSE), the Pearson correlation between the measured and predicted $\mathrm{PM}_{10}$ values $(\mathrm{CV} \mathrm{R})$ and $\mathrm{CV} \mathrm{R}^{2}$.

\section{Results}

\subsection{Model performance was highly sensitive to outliers}

To examine the influence of outliers, we fitted the temporal model (Model 1) first with all data, and next using the subset with $\mathrm{PM}_{10}$ values within the $99^{\text {th }}$ percentile. Removal of the outliers resulted in slight changes: reduced pseudo $\mathrm{R}^{2}$ (39\% to $31 \%$ ), improved marginal $\mathrm{R}^{2}$ ( $1 \%$ to $5 \%$ ). However, there was considerable decrease in RMSE $\left(19 \mu \mathrm{g} / \mathrm{m}^{3}\right.$ to $\left.7 \mu \mathrm{g} / \mathrm{m}^{3}\right)$ (Supplementary Tables 2-3), which indicated a high degree of sensitivity of the model to the inclusion of high concentration events.

Next, we assessed whether this sensitivity was observable at a state-specific scale by repeating this outlier sensitivity analysis to New South Wales, the state in Australia with the largest number of sites that also experienced the dust storm in 2009 (Supplementary Tables 4-5). For New South Wales, removal of the outliers also reduced pseudo $R^{2}\left(86 \%\right.$ to $71 \%$ ) and improved marginal $R^{2}$ (1\% to $11 \%)$ and RMSE $\left(14 \mu \mathrm{g} / \mathrm{m}^{3}\right.$ to $\left.4 \mu \mathrm{g} / \mathrm{m}^{3}\right)$. Therefore, all subsequent analyses excluded these outliers.

\subsection{Model performance did not differ after addition of Terra AOD observations}

To ascertain whether the addition of AOD sourced from Terra improved model performance, we fitted the temporal model with AOD (Model 2) first using Aqua AOD, and next using Aqua AOD 
and Terra AOD (Supplementary Table 6). Despite an improvement in the number of measurements available for analyses $(\mathrm{N}=10,091$ for Aqua AOD compared to $\mathrm{N}=16,813$ for Aqua AOD and Terra AOD), there was a negligible difference in $\mathrm{R}^{2}$ (74\% Aqua AOD, 73\% Aqua AOD and Terra AOD) and no difference in RMSE (both $4 \mu \mathrm{g} / \mathrm{m}^{3}$ ). All subsequent analyses used Aqua AOD.

\subsection{Model performance was largely attributable to ascertainment of temporal variation}

For the national model, $22 \%$ of variation in $\mathrm{PM}_{10}$ was attributed to between-day temporal variation, compared with $8 \%$ of variation in $\mathrm{PM}_{10}$ attributed to between-site spatial variation (Supplementary Table 7, Model 0). In New South Wales, $62 \%$ of variation in $\mathrm{PM}_{10}$ was attributed to temporal variation compared with $9 \%$ of variation due to spatial variation. The Australian Capital Territory, which had only two sites, had the highest percentage attributed to temporal variation ( $82 \%$ temporal versus $2 \%$ spatial). Queensland had the highest percentage attributed to spatial variation (41\% temporal versus $11 \%$ spatial).

\subsection{Model performance varied between regions}

To compare the performance of the model between regions, we fitted the spatiotemporal model (Model 4) to Australia overall as well as separately to each state and territory with at least two sites (Table 3). To facilitate comparisons between regions, we included a relative measure of RMSE expressed as a percentage of mean $\mathrm{PM}_{10}$ concentrations.

Marginal $\mathrm{R}^{2}$ did not vary substantially between regions (11\% in Western Australia versus $19 \%$ in the Australian Capital Territory), indicating that the proportion of the variance explained by the fixed effects was similar for each region. Pseudo $\mathrm{R}^{2}$ values were consistently higher than conditional $\mathrm{R}^{2}$, indicating that pseudo $\mathrm{R}^{2}$ (the most commonly reported statistic in similar studies) over-estimated the proportion of variation explained by the model. The Australian Capital Territory and Tasmania, which had only two monitoring sites each, had high pseudo $\mathrm{R}^{2}$ values but relatively low conditional $\mathrm{R}^{2}$ values. The conditional $\mathrm{R}^{2}$ for Australia overall (51\%) was lower than the regional $\mathrm{R}^{2}$ values, 
which ranged from $51 \%$ for Tasmania to $78 \%$ for South Australia.

The RMSE for Australia overall $\left(6 \mu \mathrm{g} / \mathrm{m}^{3}\right)$ was higher than for the regional models both in absolute and relative terms, indicating the value of sub-region (state) specific models. The Australian Capital Territory, Tasmania and South Australia had the lowest absolute RMSE $\left(3 \mu \mathrm{g} / \mathrm{m}^{3}\right)$ while Victoria had the lowest relative RMSE (18\%). Of the regional models, Queensland had the highest absolute and relative RMSE of $5 \mu \mathrm{g} / \mathrm{m}^{3}$ and $27 \%$ respectively.

(Table 3 here)

\subsection{Explanatory variables with greatest effects}

To facilitate comparisons of the regression coefficients, continuous predictor variables were standardized across regions to have a mean of zero and a variance of one.

For all regions except New South Wales, the Australian Capital Territory and Western Australia, the variable $A O D$ was the greatest predictor of $\mathrm{PM}_{10}$ concentrations (Table 4). In New South Wales and the Australian Capital Territory, the variable day was the greatest predictor of $\mathrm{PM}_{10}$ concentrations and indicated a downward trend in $\mathrm{PM}_{10}$ concentrations in Australia during 2006 to 2011.

(Table 4 here)

\subsection{Validation}

The results of cross-validation (LOOCV) for Model 4 for each region are shown in Supplementary Table 11. New South Wales had the highest CV R ${ }^{2}(65 \%)$ and lowest CV RMSE $\left(5 \mu \mathrm{g} / \mathrm{m}^{3}\right)$ followed by Victoria $\left(\mathrm{CV} \mathrm{R} \mathrm{R}^{2}=62 \%, \mathrm{CV} \mathrm{RMSE}=5 \mu \mathrm{g} / \mathrm{m}^{3}\right)$. This corresponds to an approximate Pearson correlation coefficient of 0.8 between actual and predicted values. Note that both New South Wales and Victoria had denser monitoring networks compared with the other regions.

The performance of the model for Australia overall $\left(\mathrm{CV} \mathrm{R}{ }^{2}=46 \%, \mathrm{CV} \mathrm{RMSE}=6 \mu \mathrm{g} / \mathrm{m}^{3}\right)$ was generally lower than the regional models, except for Western Australia, the Australian Capital 
Territory and Tasmania. The model for the largest state, Western Australia, which had only six sites, performed poorly $\left(\mathrm{CV} \mathrm{R}^{2}=29 \%, \mathrm{CV} \mathrm{RMSE}=7 \mu \mathrm{g} / \mathrm{m}^{3}\right)$. The worst-performing models were for Tasmania $\left(\mathrm{CV} \mathrm{R}^{2}=20 \%, \mathrm{CV} \mathrm{RMSE}=6 \mu \mathrm{g} / \mathrm{m}^{3}\right)$ and the Australian Capital Territory $\left(\mathrm{CV} \mathrm{R}^{2}=\right.$ $25 \%, \mathrm{CV}$ RMSE $=7 \mu \mathrm{g} / \mathrm{m}^{3}$ ), which had only two sites each and relatively few observations.

\section{Discussion}

To our knowledge, this is the first study to produce stochastic models for daily $\mathrm{PM}_{10}$ using satellitebased measurements in Australia. Our results indicated that the temporal variables, rather than spatial variables, explained most of the variation in daily $\mathrm{PM}_{10}$. For New South Wales, the state with the most sites, $62 \%$ of variation in $\mathrm{PM}_{10}$ was attributed to between-day temporal variation and $9 \%$ was attributed to between-site spatial variation. There was considerable geographic variation in the model fit, indicating the importance of sub-region (i.e. state) specific models. After accounting for both the fixed and random effects, the variation in daily $\mathrm{PM}_{10}$ explained by the model was $51 \%$ for Australia overall, and ranged from 51\% for Tasmania to $78 \%$ for South Australia. The implications of these findings for other studies are twofold. Firstly, accounting for temporal variation in $\mathrm{PM}_{10}$ levels can be critical to model fit. Secondly, models are not necessarily generalizable to different regions within the same country, and in Australia regional models are necessary.

The cross-validation results showed that the spatiotemporal model for Australia overall did not perform as well as the regional models except for Western Australia, the Australian Capital Territory and Tasmania. The cross-validation results indicated the models were relatively more appropriate for out-of-sample prediction for New South Wales and Victoria. However, the models for Western Australia, the Australian Capital Territory and Tasmania, which had few sites and observations, had lower cross-validated $\mathrm{R}^{2}$ and high RMSE values, making them less reliable for prediction.

A review of previous studies ${ }^{30}$ found that AOD is, at best, a moderate predictor of particulate matter $\left(R^{2}<0.6\right)$. However, a recent study by Lee et al. ${ }^{20}$ in the New England region of the United States 
found that satellite-based AOD predicted surface $\mathrm{PM}_{2.5}$ concentrations with an $\mathrm{R}^{2}$ of 0.83 using a mixed effects model. Another study by Yap et al. ${ }^{31}$ in peninsular Malaysia reported an $\mathrm{R}^{2}$ of 0.88 . However, for those studies it is unclear as to how much $\mathrm{R}^{2}$ increased after adding AOD to the parsimonious temporal model.

Meng et al. ${ }^{32}$ used a linear mixed effects model that included satellite-based AOD as well as meteorological and land-use variables to predict daily $\mathrm{PM}_{10}$ concentrations in 2008 in Shanghai, China. The results of land-use regression modelling indicated that green space was negatively associated with $\mathrm{PM}_{10}$ concentrations, whereas distance to the coast, $\mathrm{PM}_{10}$ emissions and length of major roads were positively associated with $\mathrm{PM}_{10}$ concentrations in Shanghai. The cross-validated $\mathrm{R}^{2}$ was 0.87 for the full model compared to 0.86 for the model without AOD and 0.83 for the model without land-use and meteorological variables. This is consistent with our results, which indicated that the inclusion of AOD and other predictor variables did not substantially improve model performance. It is possible that AOD is an important predictor of PM at certain size fractions, rather than over the whole $<10 \mu \mathrm{m}$ range. Because AOD exhibits both spatial and temporal variation, it is also plausible that including time-varying predictors accounts for some of the temporal effect of AOD on $\mathrm{PM}_{10}$.

We note that previous studies using mixed effects models have generally used pseudo $\mathrm{R}^{2}$ values, which overstate the proportion of variation explained by the model. Also, differences in the chemical composition of aerosols between regions mean that the relationship between PM and AOD will be location-specific ${ }^{33}$.

During the study period, $99 \%$ of $\mathrm{PM}_{10}$ concentrations were less than $50 \mu \mathrm{g} / \mathrm{m}^{3}$. For regional models, measurements that were $>99^{\text {th }}$ centile were inflated $\mathrm{R}^{2}$ at the cost of precision (inflated RMSE) i.e. RMSE decreased substantially when extreme values were excluded. For New South Wales, the RMSE decreased from $14 \mu \mathrm{g} / \mathrm{m}^{3}$ to $4 \mu \mathrm{g} / \mathrm{m}^{3}$. The most significant exposure event during the study 
period was a dust storm from $22^{\text {nd }}$ to $24^{\text {th }}$ September 2009 in New South Wales and parts of Queensland. During this dust storm event, daily average $\mathrm{PM}_{10}$ concentrations reached $2400 \mu \mathrm{g} / \mathrm{m}^{3}$. Sensitivity analyses to air pollution events is warranted for future studies, based on these results.

Our results showed that the effect of the predictor variables differed considerably by region. AOD was the largest predictor of $\mathrm{PM}_{10}$ concentrations for all regions except New South Wales, the Australian Capital Territory and Western Australia. The effect of AOD was highest in Queensland, where a standard deviation increase in AOD was associated with a $2 \mu \mathrm{g} / \mathrm{m}^{3}$ increase in $\mathrm{PM}_{10}$. However, in the Australian Capital Territory, AOD was not statistically significant. The effect of AOD on $\mathrm{PM}_{10}$ also differed by site within state, with $69 \%$ of variation explained by the site-varying random slope for AOD in New South Wales. Effect estimates of other predictors differed by region and included variables such as active fires, burnt area, rainfall, wind speed, temperature and industrial land use (Victoria only). Our results were consistent with a study by Johnston et al. ${ }^{34}$, which reported that bushfires were a major source of particulate air pollution in Australia. Seasonal effects also varied between regions.

A limitation of this study was that we did not account for the boundary layer height ${ }^{35}$. However, Australia is a low-lying continent and the spatial variation in altitude between monitoring sites is small. In the capital cities, where monitoring sites are concentrated and where most of the population resides, the altitude was generally less than $100 \mathrm{~m}$. A challenge for developing estimates for daily levels of $\mathrm{PM}_{10}$ in Australia is that the number of monitoring sites is limited. We accounted for this site-level variation by including random effect terms for sites ${ }^{36}$. There was also a relatively large number of missing AOD values. A consequence of this for past studies is that those models could not be readily applied by others when AOD (or any other predictor) was missing. We addressed this by reporting results for the intercepts-only model, so that estimates can be obtained when AOD is not available. In fact, contrary to past studies, we found that the gain in model fit after including fixed effects (such as AOD) was minimal in Australia. Our interpretation was that the 
intercept-only or temporal models are sufficient to account for daily $\mathrm{PM}_{10}$ variation recorded by statutory monitors. Due to missing AOD values, we quantified model improvement after including the transformed Terra AOD to the Aqua AOD distribution. However, we found that the distribution of Terra AOD differed from the Aqua AOD distribution and the inclusion of the Terra AOD values did not improve model performance.

The model choice for exposure calculation will depend on the research question of interest, but in all cases we recommend state-specific models. Cross-validation results imply that the models are best applied for out-of-sample prediction in New South Wales and Victoria. Our models are not appropriate for research questions that focus on effects of extreme PM events with concentrations $>99^{\text {th }}$ centile as these data were not included in model development as they increased RMSE considerably. However, by definition, such events occur at a rate $<37$ days per 10 years. The model remains applicable for events with concentrations $<99^{\text {th }}$ centile, and this argument is supported by the presence of active fire and burnt area variables in the models. To our knowledge this was the first study to both partition the spatial and temporal variability and apply sequential models to ascertain the benefits of increasing model complexity. The fact that applying the simpler models would result in minimal reduction in model performance provides some reassurance if predictors are unavailable. In this situation, state specific temporal models (model 1) can be applied to estimate exposure. Statespecific spatiotemporal models with site-varying AOD effects (model 4) can be applied to capture more spatial variation in exposure when those spatial data are available. 


\section{References}

1. WHO. Health effects of particulate matter. World Health Organization, 2013.

2. AlHW, Begg S, Vos T, Barker B, Stevenson C, Stanley L et al. The burden of disease and injury in Australia 2003. Australian Institute of Health and Welfare, 2007.

3. Barnett AG, Williams GM, Schwartz J, Neller AH, Best TL, Petroeschevsky AL et al Air pollution and child respiratory health: a case-crossover study in Australia and New Zealand. American Journal of Respiratory and Critical Care Medicine 2005; 171: 1272-1278.

4. Crabbe H Risk of respiratory and cardiovascular hospitalisation with exposure to bushfire particulates: new evidence from Darwin, Australia. Environmental Geochemistry And Health 2012; 34: 697-709.

5. Pereira G, Cook A, de Vos AJBM, Holman CDJ A case-crossover analysis of traffic-related air pollution and emergency department presentations for asthma in Perth, Western Australia. Medical Journal Of Australia 2010; 193: 511-514.

6. Bell ML, Ebisu K, Belanger K Ambient air pollution and low birth weight in Connecticut and Massachusetts. Environmental health perspectives 2007. 1118-1124.

7. Simpson R Maternal exposure to low levels of ambient air pollution and preterm birth in Brisbane, Australia. BJOG 2006; 113: 935-941.

8. Hamra GB, Guha N, Cohen A, Laden F, Raaschou-Nielsen O, Samet JM et al Outdoor particulate matter exposure and lung cancer: a systematic review and meta-analysis. Environmental Health Perspectives 2014; 122: 906-911.

9. Dennekamp M, Abramson MJ The effects of bushfire smoke on respiratory health. Respirology 2011; 16: 198-209.

10. Merrifield A, Schindeler S, Jalaludin B, Smith W Health effects of the September 2009 dust storm in Sydney, Australia: did emergency department visits and hospital admissions increase? Environ Health 2013; 12: 32.

11. Pereira G, Nassar N, Bower C, Weinstein P, Cook A Residential exposure to traffic emissions and adverse pregnancy outcomes. SAPI EN S Surveys and Perspectives Integrating Environment and Society 2010.

12. Knibbs LD, Hewson MG, Bechle MJ, Marshall JD, Barnett AG A national satellite-based land-use regression model for air pollution exposure assessment in Australia. Environmental Research 2014; 135: 204-211.

13. Ebisu K, Belanger K, Bell ML Association between airborne PM2. 5 chemical constituents and birth weight-implication of buffer exposure assignment. Environmental Research Letters 2014; 9: 084007.

14. Hoek G, Beelen R, de Hoogh K, Vienneau D, Gulliver J, Fischer P et al A review of land-use regression models to assess spatial variation of outdoor air pollution. Atmos Environ 2008; 42: 7561-7578.

15. Ryan PH, LeMasters GK A review of land-use regression models for characterizing intraurban air 
pollution exposure. Inhal Toxicol 2007; 19: 127-133.

16. Liu Y, Sarnat JA, Kilaru V, Jacob DJ, Koutrakis P Estimating ground-level PM2. 5 in the eastern United States using satellite remote sensing. Environmental science \& technology 2005; 39: 3269-3278.

17. Li J, Carlson BE, Lacis AA How well do satellite AOD observations represent the spatial and temporal variability of PM 2.5 concentration for the United States? Atmospheric Environment 2015; 102: 260273.

18. Hystad P, Setton E, Carvantes A, Poplawski K, Deschenes S, Brauer M Creating national air pollution models for population exposure assessment in Canada. Environ Health Perspect 2011; 119: 11231129.

19. Ma Z, Hu X, Sayer AM, Levy R, Zhang Q, Xue Y et al Satellite-based spatiotemporal trends in PM2. 5 concentrations: China, 2004-2013. Environ Health Perspect 2015.

20. Lee HJ, Coull BA, Bell ML, Koutrakis P Use of satellite-based aerosol optical depth and spatial clustering to predict ambient PM2.5 concentrations. Environmental Research 2012; 118: 8-15.

21. PRC. Collection and Reporting of TEOM PM10 Data.

http://www.scew.gov.au/system/files/resources/9947318f-af8c-0b24-d928-

04e4d3a4b25c/files/aaqprctp10collectionandreporting200105final.pdf.

22. Allen G, Sioutas C, Koutrakis P, Reiss R, Lurmann FW, Roberts PT Evaluation of the TEOM ${ }^{\circledR}$ method for measurement of ambient particulate mass in urban areas. Journal of the Air \& Waste Management Association 1997; 47: 682-689.

23. AQEG. Particulate Matter in the UK: Summary. Defra: London, 2005.

24. Levy R, Mattoo S, Munchak L, Remer L, Sayer A, Hsu N The Collection 6 MODIS aerosol products over land and ocean. Atmos Meas Tech 2013; 6: 2989-3034.

25. Hsu N, Jeong MJ, Bettenhausen C, Sayer A, Hansell R, Seftor C et al Enhanced Deep Blue aerosol retrieval algorithm: The second generation. Journal of Geophysical Research: Atmospheres 2013; 118: 9296-9315.

26. Sayer A, Hsu N, Bettenhausen C, Jeong MJ Validation and uncertainty estimates for MODIS Collection 6 “Deep Blue” aerosol data. Journal of Geophysical Research: Atmospheres 2013; 118: 7864-7872.

27. Nakagawa S, Schielzeth H A general and simple method for obtaining R2 from generalized linear mixed-effects models. Methods in Ecology and Evolution 2013; 4: 133-142.

28. Johnson PC Extension of Nakagawa \& Schielzeth's R2GLMM to random slopes models. Methods in Ecology and Evolution 2014; 5: 944-946.

29. Tibshirani R Regression shrinkage and selection via the Lasso. JRStatSocB 1996; 58: 267-288.

30. Hoff RM, Christopher SA Remote sensing of particulate pollution from space: Have we reached the promised land? J Air Waste Manag Assoc 2009; 59: 645-675.

31. Yap X, Hashim M A robust calibration approach for PM 10 prediction from MODIS aerosol optical 
depth. Atmospheric Chemistry and Physics Discussions 2012; 12: 31483-31505.

32. Meng $\mathrm{X}$, Fu Q, Ma Z, Chen L, Zou B, Zhang Y et al Estimating ground-level PM 10 in a Chinese city by combining satellite data, meteorological information and a land use regression model. Environmental Pollution 2016; 208: 177-184.

33. Guo JP, Zhang XY, Che HZ, Gong SL, An X, Cao CX et al Correlation between PM concentrations and aerosol optical depth in eastern China. Atmos Environ 2009; 43: 5876-5886.

34. Johnston FH, Hanigan IC, Henderson SB, Morgan GG, Portner T, Williamson GJ et al Creating an integrated historical record of extreme particulate air pollution events in Australian cities from 1994 to 2007. Journal of the Air \& Waste Management Association 2011; 61: 390-398.

35. Tsai T-C, Jeng Y-J, Chu DA, Chen J-P, Chang S-C Analysis of the relationship between MODIS aerosol optical depth and particulate matter from 2006 to 2008. Atmospheric Environment 2011; 45: 47774788.

36. Lee HJ, Liu Y, Coull BA, J S, Koutrakis P A novel calibration approach of MODIS AOD data to predict PM2.5 concentrations. Atmospheric Chemistry and Physics 2011; 11: 7991-8002.

37. Geoscience Australia. 1 second SRTM Derived Products User Guide.

http://www.ga.gov.au/corporate data/72759/1secSRTM Derived DEMs UserGuide v1.0.4.pdf.

38. DiMiceli CM, Carroll ML, Sohlberg RA, Huang C, Hansen MC, Townshend JRG. Annual Global Automated MODIS Vegetation Continuous Fields (MOD44B) at $250 \mathrm{~m}$ Spatial Resolution for Data Years Beginning Day 65, 2000 - 2010, Collection 5 Percent Tree Cover. http://www.landcover.org/data/vcf/.

39. Elvidge CD, Tuttle BT, Sutton PC, Baugh KE, Howard AT, Milesi C et al Global distribution and density of constructed impervious surfaces. Sensors 2007; 7: 1962-1979.

40. Public Sector Mapping Agencies. Transport and Topography Data Product Description. http://www.psma.com.au/psma/wp-content/uploads/Transport-and-Topography-ProductDescription.pdf

41. Giglio L MODIS collection 5 active fire product user's guide version 2.4. Science Systems and Applications, Inc 2010.

42. MODIS-Landsat data fusion for automated continental $30 \mathrm{~m}$ burned area mapping. AGU Fall Meeting Abstracts, 2013.

43. Rose N, Cowie C, Gillett R, Marks GB Validation of a spatiotemporal land use regression model incorporating fixed site monitors. Environmental science \& technology 2010; 45: 294-299.

44. Novotny EV, Bechle MJ, Millett DB, Marshall JD National satellite-based land-use regression: NO2 in the United States. Environ Sci Technol 2011; 45: 4407-4414. 


\section{Supplementary Material}

Figure S1a: Australian states and site locations.

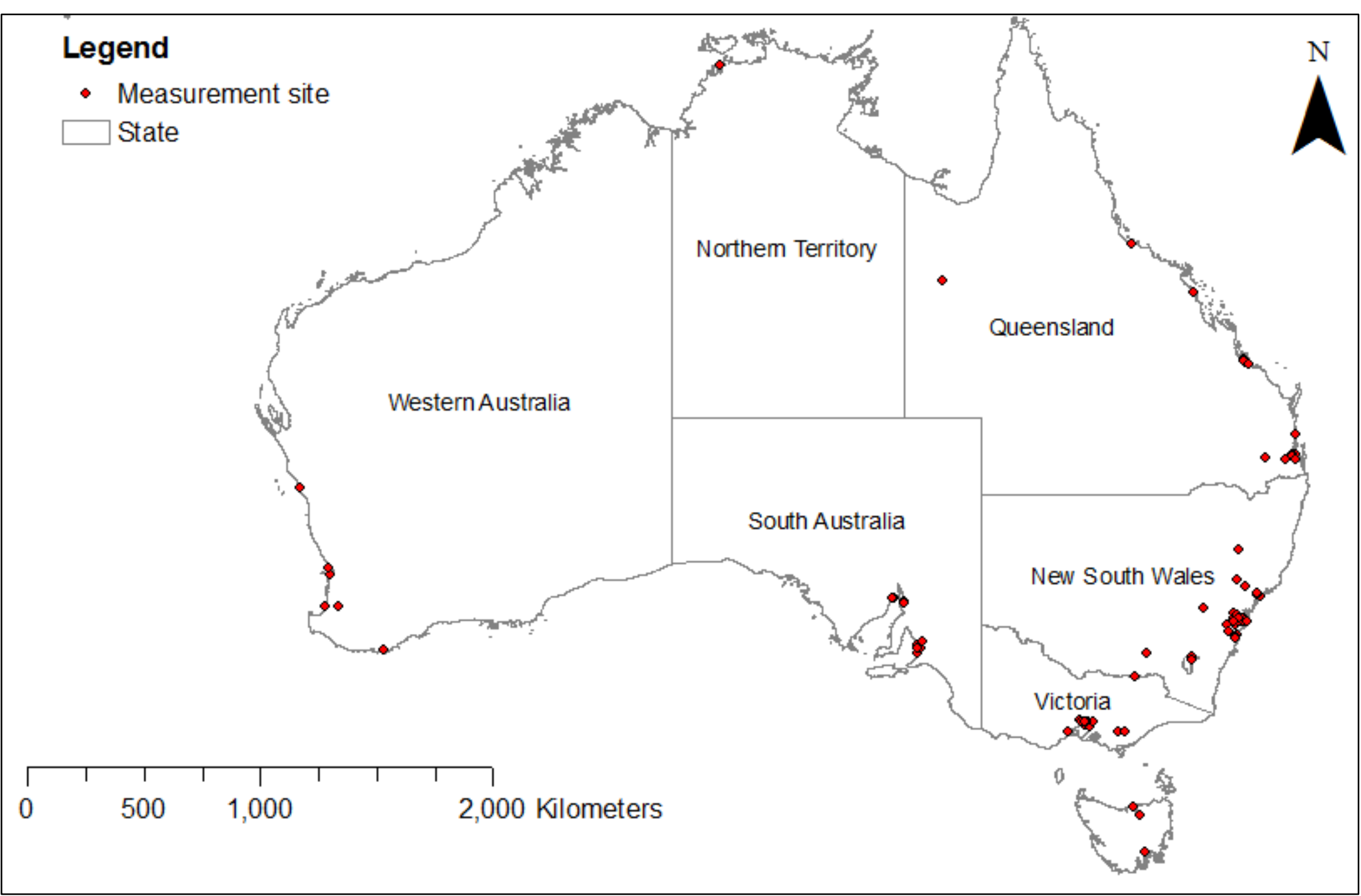


Figure S1b: Site locations in the south-east of mainland Australia

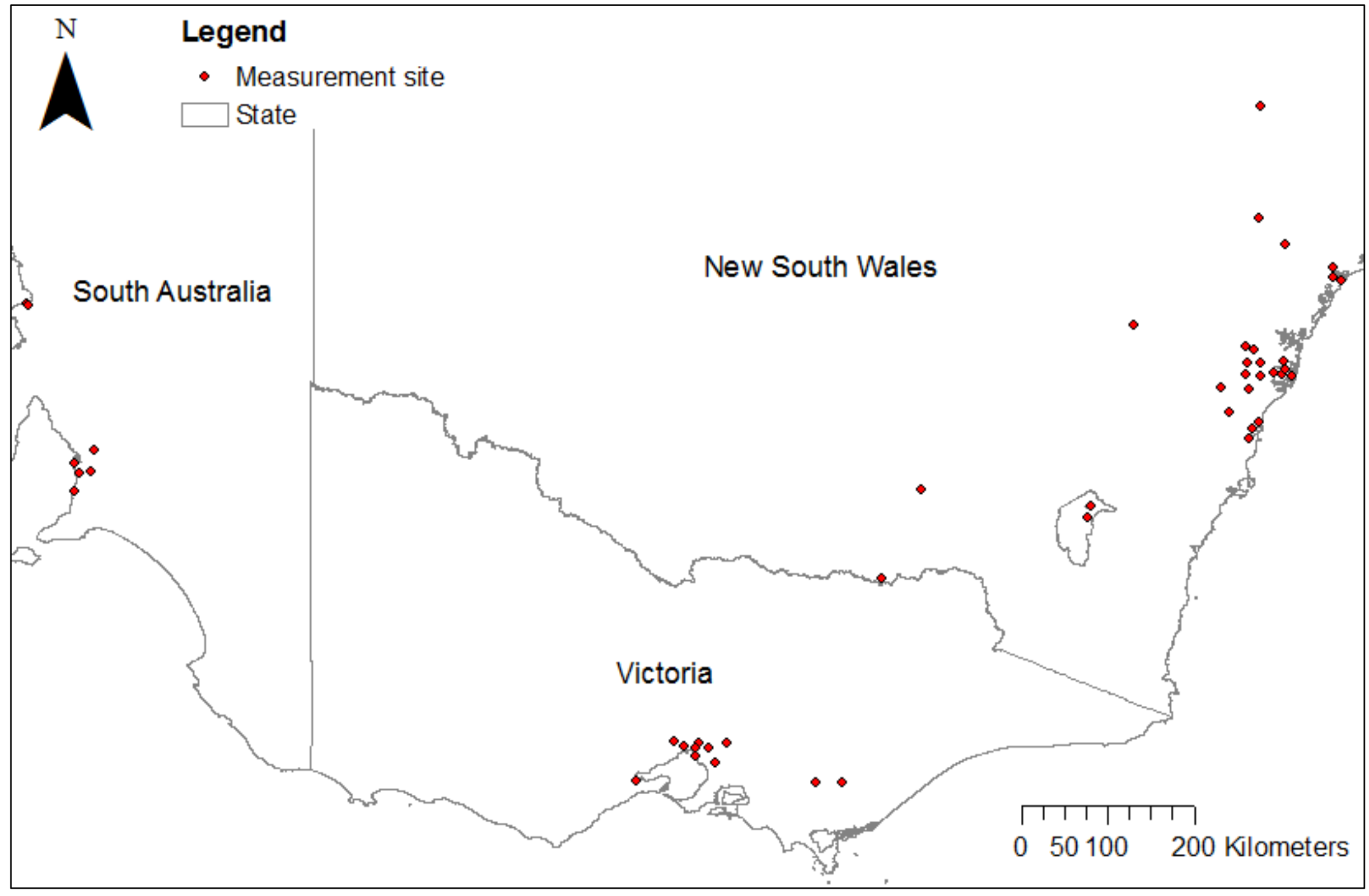


Figure S2: Time series of $\mathrm{PM}_{10}\left(\mu \mathrm{g} / \mathrm{m}^{3}\right)$ concentrations during the study period (black lines) with linear trend (blue lines) for four sites.
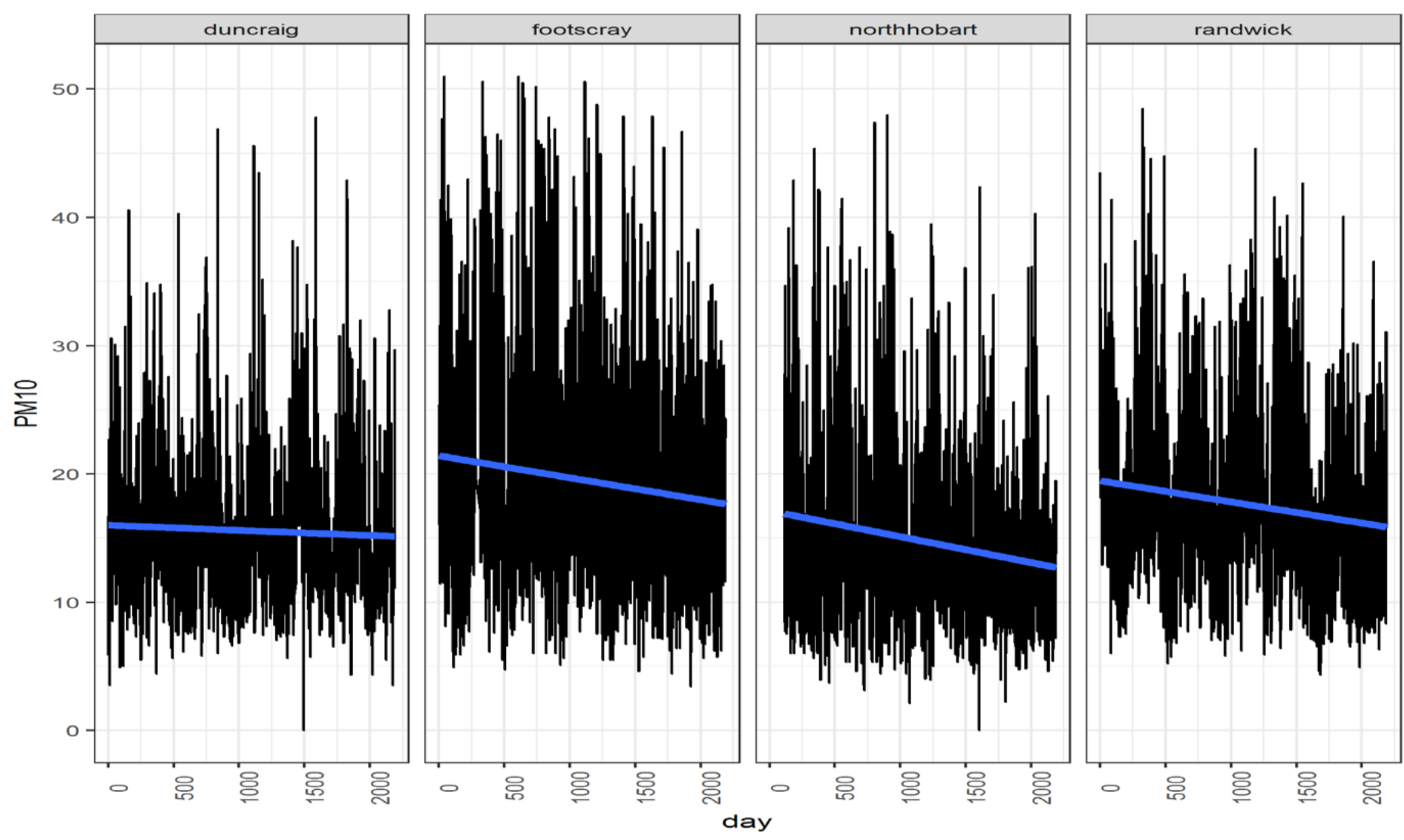
Figure S3: Boxplots of $\mathrm{PM}_{10}$ concentrations $\left(\mu \mathrm{g} / \mathrm{m}^{3}\right)$ by season and year for all sites.
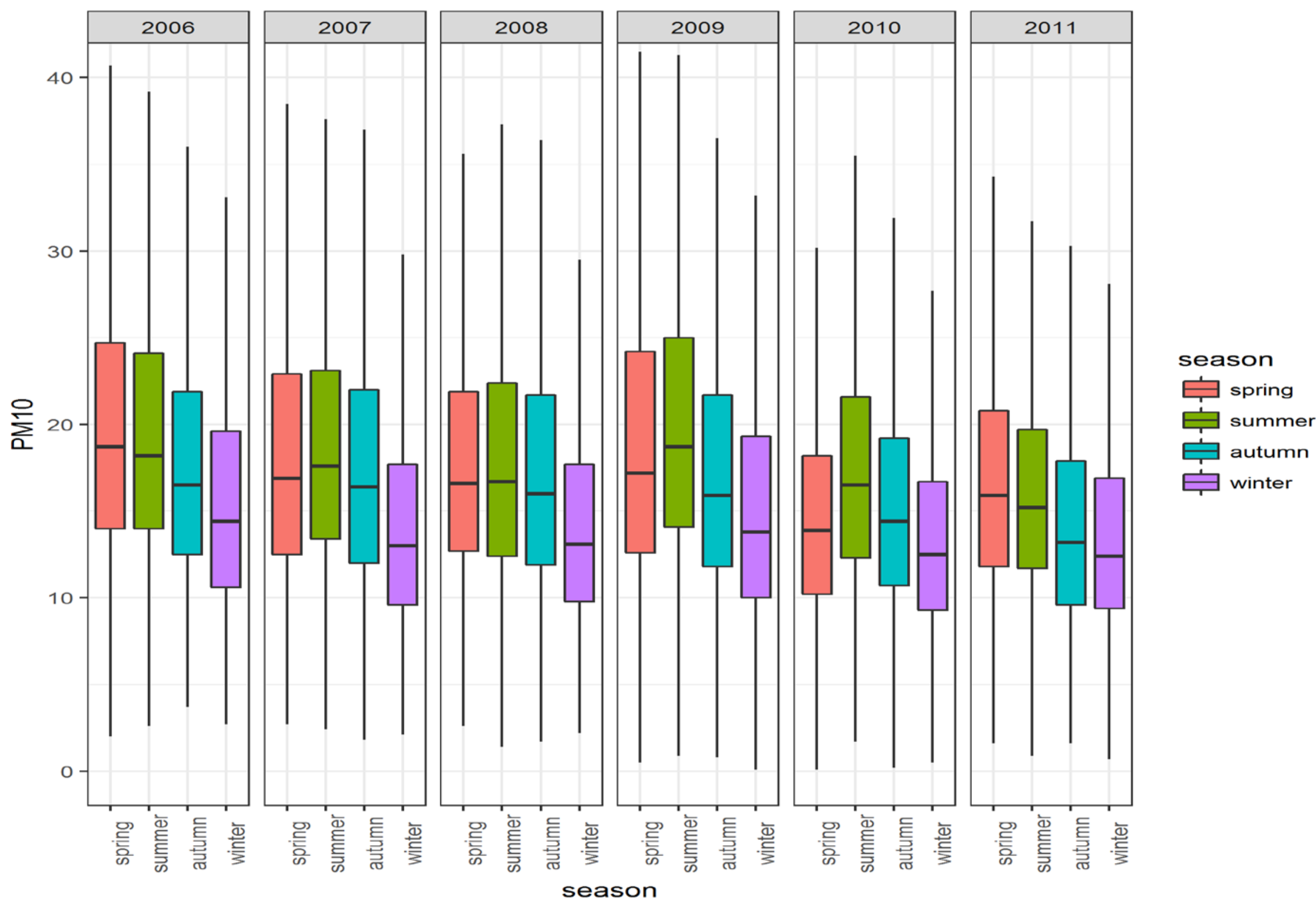
Table S1: The type and source of independent land-use variables considered in the model.

\begin{tabular}{|c|c|c|c|}
\hline Variable (units) & Resolution & $\begin{array}{l}\text { Point or } \\
\text { buffer } \\
\text { estimate }\end{array}$ & Source (all websites accessed on 02-Apr-2014) \\
\hline elevation (m) & $30 \mathrm{~m}$ & point & $\begin{array}{l}\text { Geoscience Australia 1-second smoothed digital elevation model derived from SRTM } \\
\text { http://www.ga.gov.au/metadata-gateway/metadata/record/gcat_72759 }\end{array}$ \\
\hline distance to coast $(\mathrm{km})$ & - & point & Derived using 'Near' command in ArcGIS (excludes inland lakes) \\
\hline $\begin{array}{l}\text { annual, seasonal \& monthly mean } \\
\text { rainfall (mm) }\end{array}$ & $2.5 \mathrm{~km}$ & point & Australian Bureau of Meteorology http://www.bom.gov.au/jsp/ncc/climate_averages/rainfall/index.jsp \\
\hline $\begin{array}{l}\text { annual, seasonal \& monthly mean } \\
\text { daily average temperature }\left({ }^{\circ} \mathrm{C}\right)^{\mathrm{a}}\end{array}$ & $2.5 \mathrm{~km}$ & point & Australian Bureau of Meteorology http://www.bom.gov.au/jsp/ncc/climate_averages/temperature/index.jsp \\
\hline $\begin{array}{l}\text { annual, seasonal \& monthly mean } \\
\text { daily solar exposure }\left(\mathrm{MJ} / \mathrm{m}^{2}\right)\end{array}$ & $5 \mathrm{~km}$ & point & $\begin{array}{l}\text { Australian Bureau of Meteorology } \\
\text { http://www.bom.gov.au/jsp/ncc/climate_averages/solar-exposure/index.jsp }\end{array}$ \\
\hline $\begin{array}{l}\text { annual and monthly mean wind } \\
\text { speed }(\mathrm{km} / \mathrm{h})\end{array}$ & $12.5 \mathrm{~km}$ & point & $\begin{array}{l}\text { Australian Bureau of Meteorology Average monthly wind velocity grids (2004-2008) } \\
\text { http://www.bom.gov.au/climate/averages/climatology/gridded-data-info/metadata/md ave_windvelocity-2004- } \\
\text { 2008.shtml }\end{array}$ \\
\hline *tree cover (\%) & $250 \mathrm{~m}$ & bufferg $^{g}$ & $\begin{array}{l}\text { MODIS-derived vegetation continuous fields product for } 2006^{34} \\
\text { http://www.landcover.org/data/vcf/ }\end{array}$ \\
\hline *impervious surfaces (\%) & $1 \mathrm{~km}$ & bufferg $^{g}$ & $\begin{array}{l}\text { NOAA constructed impervious surface area product 2000-2001 } 35 \\
\text { http://ngdc.noaa.gov/eog/dmsp/download_global_isa.html }\end{array}$ \\
\hline$*$ major roads $(\mathrm{km})^{\mathrm{b} \#}$ & - & bufferg $^{g}$ & $\begin{array}{l}\text { PSMA Australia Transport and Topography product**36 } \\
\text { http://www.psma.com.au/?product=transport-topography }\end{array}$ \\
\hline$*$ minor roads $(\mathrm{km})^{\mathrm{c} \#}$ & - & bufferg $^{g}$ & " " \\
\hline $\begin{array}{l}\text { *total roads }(=\text { major roads }+ \\
\text { minor roads })(\mathrm{km})\end{array}$ & - & buffer $^{g}$ & " " \\
\hline *unsealed roads $(\mathrm{km})^{\#}$ & - & buffer ${ }^{g}$ & " " \\
\hline $\begin{array}{l}\text { *population density } \\
\text { (persons } / \mathrm{km}^{2} \text { ) }\end{array}$ & mesh block ${ }^{\mathrm{e}}$ & buffer $^{f}$ & $\begin{array}{l}\text { Australian Bureau of Statistics } 2011 \text { Census } \\
\text { http://www.abs.gov.au/census }\end{array}$ \\
\hline *land use type (\%) ${ }^{\mathrm{d}}$ & mesh block ${ }^{\mathrm{e}}$ & buffer ${ }^{g}$ & " " \\
\hline *water cover $(\%)$ & $250 \mathrm{~m}$ & bufferg & $\begin{array}{l}\text { MODIS-derived vegetation continuous fields product for } 2006^{34} \\
\text { http://www.landcover.org/data/vcf/ }\end{array}$ \\
\hline $\begin{array}{l}\text { *industrial point source } \mathrm{PM}_{10} \\
\text { emissions (sites } / \mathrm{km}^{2} \text { ) }\end{array}$ & - & bufferg & $\begin{array}{l}\text { Australia National Pollutant Inventory 2008/9 } \\
\text { http://www.npi.gov.au/ }\end{array}$ \\
\hline
\end{tabular}




\begin{tabular}{|c|c|c|c|}
\hline $\begin{array}{l}\text { *industrial point source } \mathrm{PM}_{10} \\
\text { emissions (kg/year) }\end{array}$ & - & bufferg & " " \\
\hline $\begin{array}{l}\text { distance to nearest industrial } \\
\mathrm{PM}_{10} \text { point source }(\mathrm{km})\end{array}$ & - & point & " " \\
\hline $\begin{array}{l}\text { distance to nearest coal-fired } \\
\text { power station }(\mathrm{km})\end{array}$ & - & point & $\begin{array}{l}\text { Geoscience Australia National Power Stations Database } \\
\text { http://www.ga.gov.au/metadata-gateway/metadata/record/gcat_04661f51-82ee-144e-e054- } \\
\underline{\text { 00144fdd4fa6/National+Power+Stations+Database }}\end{array}$ \\
\hline $\begin{array}{l}\text { distance to nearest power station } \\
\text { (non-wind, water or solar) }(\mathrm{km})\end{array}$ & - & point & $\begin{array}{l}\text { Geoscience Australia National Power Stations Database } \\
\text { http://www.ga.gov.au/metadata-gateway/metadata/record/gcat_04661f51-82ee-144e-e054- } \\
\underline{\text { 00144fdd4fa6/National+Power+Stations+Database }}\end{array}$ \\
\hline $\begin{array}{l}* * * \text { active fires (annual and } \\
\text { monthly average) (number of) }\end{array}$ & $1 \mathrm{~km}$ & buffer ${ }^{g}$ & $\begin{array}{l}\text { MODIS Collection } 5 \text { Monthly Fire Location Product (MCD14ML) } \dagger{ }^{37} \\
\text { https://earthdata.nasa.gov/earth-observation-data/near-real-time/firms/active-fire-data }\end{array}$ \\
\hline $\begin{array}{l}* * * \text { burnt area (annual and } \\
\text { monthly average) }\left(\mathrm{km}^{2}\right)\end{array}$ & $500 \mathrm{~m}$ & buffer ${ }^{g}$ & $\begin{array}{l}\text { MODIS Collection 5.1 Burned Area Product (MCD45) } \ddagger^{38} \\
\text { http://modis-fire.umd.edu/pages/BurnedArea.php }\end{array}$ \\
\hline
\end{tabular}

a average daily minimum and maximum temperature were also included in the model

${ }^{\mathrm{b}}$ major roads were defined as national/state highways, arterial roads (which are major connector roads for national and state highways) and sub-arterial roads (which are connectors between highways and/or arterial roads, or serve as an alternative for arterial roads) ${ }^{36}$

${ }^{\mathrm{c}}$ minor roads were defined as collector roads (which are connectors between sub-arterial roads, and distribute traffic to local roads) and local roads (which provide property access) ${ }^{36}$. The distance to the nearest minor road was also included as a candidate variable.

${ }^{\mathrm{d}}$ four land use categories were examined - residential, commercial, industrial, and open space (which was the sum of water, parks and agricultural land ${ }^{39}$ )

e a mesh block is the smallest spatial unit used in the Australian census and their size varies - on average they contain 62 people.

f average of variable within buffe

$\mathrm{g}$ sum of variable within buffer

* 25 circular buffers were created with radii of 100 m, 200 m, 300 m, 400 m, 500 m, 600 m, 700 m, 800 m, 1000 m, 1200 m, 1500 m, 1800 m, 2000 m, 2500 m, 3000 m, 3500 m, 4000 m, 5000 m, 6000 m, 7000 m, $8000 \mathrm{~m}, 10,000 \mathrm{~m}, 20,000 \mathrm{~m}, 50,000 \mathrm{~m}$ and $100,000 \mathrm{~m}^{40}$

** Positional accuracy is $\pm 2 \mathrm{~m}$ in urban areas, $\pm 10 \mathrm{~m}$ in rural and remote areas. Attribute accuracy is $99.09 \%$ for key attributes (name and unique identifier) ${ }^{36}$

*** For active fire and burnt area, 5 circular buffers were created with radii of $10 \mathrm{~km}, 20 \mathrm{~km}, 50 \mathrm{~km}, 100 \mathrm{~km}$ and $250 \mathrm{~km}$.

$\dagger$ All active fire pixels with a detection confidence score $\geq 30$ (nominal to high confidence range) ${ }^{37}$.

$\ddagger$ All burnt area pixels with a quality assurance code of $1,2,3$, or 438 .

\# The distance (metres) to the nearest major, minor and unsealed roads was also included as a candidate variable. 
Table S2: Results of models for daily $\mathbf{P M}_{10}$ fitted to all observations in Australia.

\begin{tabular}{|c|c|c|c|c|c|c|c|c|c|c|}
\hline \multirow[b]{2}{*}{ Model } & \multicolumn{5}{|c|}{$\begin{array}{l}\text { All days in study period } \\
\qquad \mathrm{n}=143,129\end{array}$} & \multicolumn{5}{|c|}{$\begin{array}{l}\text { Days in study period with Aqua AOD available } \\
\qquad n=23,833\end{array}$} \\
\hline & $\mathrm{R}^{2}$ & $\mathrm{R}_{\mathrm{m}}^{2}$ & $\mathrm{R}_{\mathrm{C}}^{2}$ & RMSE & $\mathrm{BIC}$ & $\mathrm{R}^{2}$ & $\mathrm{R}_{\mathrm{m}}^{2}$ & $\mathrm{R}^{2}{ }_{\mathrm{c}}$ & RMSE & $\mathrm{BIC}$ \\
\hline 0 & $39 \%$ & $0 \%$ & $37 \%$ & 19 & 1266821 & $47 \%$ & $0 \%$ & $43 \%$ & 15 & 203783 \\
\hline 1 & $39 \%$ & $1 \%$ & $37 \%$ & 19 & 1266813 & $47 \%$ & $2 \%$ & $43 \%$ & 15 & 203754 \\
\hline 2 & - & - & - & - & - & $48 \%$ & $5 \%$ & $45 \%$ & 15 & 202985 \\
\hline 3 & - & - & - & - & - & $50 \%$ & $5 \%$ & $47 \%$ & 15 & 202598 \\
\hline 4 & - & - & - & - & - & $50 \%$ & $7 \%$ & $48 \%$ & 15 & 202364 \\
\hline
\end{tabular}

Table S3: Results of models fitted to observations in Australia with $\mathbf{P M}_{10}$ values within the $99^{\text {th }}$ percentile.

\begin{tabular}{|c|c|c|c|c|c|c|c|c|c|c|}
\hline \multirow[b]{2}{*}{ Model } & \multirow[b]{2}{*}{$\mathrm{R}^{2}$} & \multirow[b]{2}{*}{$\mathrm{R}^{2} \mathrm{~m}$} & \multicolumn{3}{|c|}{$\begin{array}{l}\text { All days in study period } \\
n=141,700\end{array}$} & \multicolumn{5}{|c|}{$\begin{array}{l}\text { Days in study period with Aqua AOD available } \\
\qquad n=23,472\end{array}$} \\
\hline & & & $\mathrm{R}^{2} \mathrm{C}$ & RMSE & BIC & $\mathrm{R}^{2}$ & $\mathrm{R}^{2} \mathrm{~m}$ & $\mathrm{R}^{2} \mathrm{C}$ & RMSE & BIC \\
\hline 0 & $31 \%$ & $0 \%$ & $31 \%$ & 7 & 945589 & $52 \%$ & $0 \%$ & $47 \%$ & 6 & 156209 \\
\hline 1 & $31 \%$ & $5 \%$ & $31 \%$ & 7 & 945094 & $52 \%$ & $6 \%$ & $47 \%$ & 6 & 155925 \\
\hline 2 & - & - & - & - & - & $53 \%$ & $10 \%$ & $48 \%$ & 6 & 155178 \\
\hline 3 & - & - & - & - & - & $54 \%$ & $10 \%$ & $50 \%$ & 6 & 154959 \\
\hline 4 & - & - & - & - & - & $55 \%$ & $11 \%$ & $51 \%$ & 6 & 154642 \\
\hline
\end{tabular}

Table S4: Results of models for daily PM10 fitted to all observations in NSW.

\begin{tabular}{|c|c|c|c|c|c|c|c|c|c|c|}
\hline \multirow[b]{2}{*}{ Model } & \multicolumn{5}{|c|}{$\begin{array}{l}\text { All days in study period } \\
n=49,633\end{array}$} & \multicolumn{5}{|c|}{$\begin{array}{l}\text { Days in study period with Aqua AOD available } \\
\qquad n=10,222\end{array}$} \\
\hline & $\mathrm{R}^{2}$ & $\mathrm{R}_{\mathrm{m}}^{2}$ & $\mathrm{R}^{2}{ }_{\mathrm{c}}$ & RMSE & BIC & $\mathrm{R}^{2}$ & $\mathrm{R}_{\mathrm{m}}^{2}$ & $\mathrm{R}^{2}{ }_{\mathrm{c}}$ & RMSE & BIC \\
\hline 0 & $86 \%$ & $0 \%$ & $85 \%$ & 14 & 413959 & $91 \%$ & $0 \%$ & $96 \%$ & 7 & 76509 \\
\hline 1 & $86 \%$ & $1 \%$ & $85 \%$ & 14 & 413978 & $91 \%$ & $1 \%$ & $96 \%$ & 7 & 76528 \\
\hline 2 & - & - & - & - & - & $91 \%$ & $1 \%$ & $96 \%$ & 7 & 76373 \\
\hline 3 & - & - & - & - & - & $92 \%$ & $1 \%$ & $96 \%$ & 6 & 75995 \\
\hline 4 & - & - & - & - & - & $92 \%$ & $2 \%$ & $96 \%$ & 6 & 75849 \\
\hline
\end{tabular}

Table S5: Results of models fitted to observations in NSW with PM $_{10}$ values within the $99^{\text {th }}$ percentile.

\begin{tabular}{|c|c|c|c|c|c|c|c|c|c|c|}
\hline \multirow[b]{2}{*}{ Model } & \multirow[b]{2}{*}{$\mathrm{R}^{2}$} & \multirow[b]{2}{*}{$\mathrm{R}^{2} \mathrm{~m}$} & \multicolumn{3}{|c|}{$\begin{array}{l}\text { All days in study period } \\
\qquad \mathrm{n}=49,140\end{array}$} & \multicolumn{5}{|c|}{$\begin{array}{l}\text { Days in study period with Aqua AOD available } \\
\qquad n=10,091\end{array}$} \\
\hline & & & $\mathrm{R}^{2} \mathrm{C}$ & RMSE & BIC & $\mathrm{R}^{2}$ & $\mathrm{R}^{2} \mathrm{~m}$ & $\mathrm{R}^{2} \mathrm{C}$ & RMSE & $\mathrm{BIC}$ \\
\hline 0 & $71 \%$ & $0 \%$ & $71 \%$ & 4 & 292402 & $74 \%$ & $0 \%$ & $70 \%$ & 4 & 62825 \\
\hline 1 & $71 \%$ & $11 \%$ & $71 \%$ & 4 & 292020 & $74 \%$ & $11 \%$ & $71 \%$ & 4 & 62589 \\
\hline 2 & - & - & - & - & - & $74 \%$ & $12 \%$ & $71 \%$ & 4 & 62493 \\
\hline 3 & - & - & - & - & - & $75 \%$ & $13 \%$ & $72 \%$ & 4 & 62290 \\
\hline 4 & - & - & - & - & - & $75 \%$ & $13 \%$ & $72 \%$ & 4 & 62271 \\
\hline
\end{tabular}


Table S6: Results of models fitted to NSW data with PM 10 values within the $\mathbf{9 9}^{\text {th }}$ percentile - Aqua versus Terra AOD.

\begin{tabular}{|c|c|c|c|c|c|c|c|c|c|c|}
\hline \multirow[b]{2}{*}{ Model } & \multicolumn{5}{|c|}{$\begin{array}{l}\text { Days in study period with Aqua and/or Terra } \\
\qquad \mathrm{n}=16,813\end{array}$} & \multicolumn{5}{|c|}{$\begin{array}{l}\text { Days in study period with Aqua AOD available } \\
\qquad \mathrm{n}=10,091\end{array}$} \\
\hline & $\mathrm{R}^{2}$ & $\mathrm{R}_{\mathrm{m}}^{2}$ & $\mathrm{R}_{\mathrm{C}}^{2}$ & RMSE & BIC & $\mathrm{R}^{2}$ & $\mathrm{R}_{\mathrm{m}}^{2}$ & $\mathrm{R}_{\mathrm{C}}^{2}$ & RMSE & $\mathrm{BIC}$ \\
\hline 0 & $73 \%$ & $0 \%$ & $71 \%$ & 4 & 103589 & $74 \%$ & $0 \%$ & $70 \%$ & 4 & 62825 \\
\hline 1 & $73 \%$ & $10 \%$ & $71 \%$ & 4 & 103306 & $74 \%$ & $11 \%$ & $71 \%$ & 4 & 62589 \\
\hline 2 & $73 \%$ & $11 \%$ & $71 \%$ & 4 & 103221 & $74 \%$ & $12 \%$ & $71 \%$ & 4 & 62493 \\
\hline 3 & $74 \%$ & $11 \%$ & $72 \%$ & 4 & 102943 & $75 \%$ & $13 \%$ & $72 \%$ & 4 & 62290 \\
\hline 4 & $74 \%$ & $12 \%$ & $72 \%$ & 4 & 102842 & $75 \%$ & $13 \%$ & $72 \%$ & 4 & 62271 \\
\hline
\end{tabular}

Table S7: Estimates of the variance components (\% of total variation) for Model 0 fitted to all observations with $\mathbf{P M}_{10}$ values within the $99^{\text {th }}$ percentile by location.

\begin{tabular}{l|rrr}
\hline & \multicolumn{3}{|c}{ All days in study period } \\
& $\sigma^{2}\left(v_{0 j}\right)$ & $\sigma^{2}\left(u_{0 i}\right)$ & $\sigma^{2}$ (residual) \\
\hline Australia & $22 \%$ & $8 \%$ & $70 \%$ \\
NSW & $62 \%$ & $9 \%$ & $29 \%$ \\
QLD & $41 \%$ & $11 \%$ & $48 \%$ \\
VIC & $72 \%$ & $3 \%$ & $25 \%$ \\
SA & $68 \%$ & $3 \%$ & $29 \%$ \\
WA & $42 \%$ & $10 \%$ & $48 \%$ \\
ACT & $82 \%$ & $2 \%$ & $16 \%$ \\
TAS & $51 \%$ & $2 \%$ & $47 \%$ \\
\hline \multicolumn{2}{r}{$v_{0 j}=$ random intercept for day $j, u_{0 i}=$ random intercept for site $i}$,
\end{tabular}

Table S8: Estimates of the variance components ( $\%$ of total variation) for models fitted to all observations in Australia with $\mathbf{P M}_{10}$ values within the $99^{\text {th }}$ percentile.

\begin{tabular}{l|rrr|crrr}
\hline & \multicolumn{3}{|c|}{ All days in study period } & \multicolumn{4}{c}{ Days in study period with Aqua AOD available } \\
Model & \multicolumn{3}{|c|}{$\mathrm{n}=141,700$} & \multicolumn{4}{c}{ n=23,472 } \\
& $\sigma^{2}\left(v_{0 j}\right)$ & $\sigma^{2}\left(u_{0 i}\right)$ & $\sigma^{2}$ (residual) & $\sigma^{2}\left(v_{0 j}\right)$ & $\sigma^{2}\left(u_{0 i}\right)$ & $\sigma^{2}\left(u_{1 i}\right)$ & $\sigma^{2}$ (residual) \\
\hline 0 & $22 \%$ & $8 \%$ & $70 \%$ & $34 \%$ & $13 \%$ & - & $53 \%$ \\
1 & $18 \%$ & $9 \%$ & $73 \%$ & $31 \%$ & $13 \%$ & - & $56 \%$ \\
2 & - & - & - & $30 \%$ & $13 \%$ & - & $57 \%$ \\
3 & - & - & - & $10 \%$ & $5 \%$ & $65 \%$ & $20 \%$ \\
4 & - & - & - & $12 \%$ & $6 \%$ & $61 \%$ & $21 \%$ \\
\hline \multicolumn{7}{l}{$v_{0 j}=$}
\end{tabular}

Table S9: Estimates of the variance components (\% of total variation) for models fitted to all observations in NSW with $\mathrm{PM}_{10}$ values within the $99^{\text {th }}$ percentile.

\begin{tabular}{|c|c|c|c|c|c|c|c|}
\hline \multirow[b]{2}{*}{ Model } & \multicolumn{3}{|c|}{$\begin{array}{l}\text { All days in study period } \\
\mathrm{n}=49,140\end{array}$} & \multicolumn{4}{|c|}{$\begin{array}{l}\text { Days in study period with Aqua AOD available } \\
\qquad n=10,091\end{array}$} \\
\hline & $\sigma^{2}\left(v_{0 j}\right)$ & $\sigma^{2}\left(u_{0 i}\right)$ & $\sigma^{2}$ (residual) & $\sigma^{2}\left(v_{0 j}\right)$ & $\sigma^{2}\left(u_{0 i}\right)$ & $\sigma^{2}\left(u_{1 i}\right)$ & $\sigma^{2}$ (residual) \\
\hline 0 & $62 \%$ & $9 \%$ & $29 \%$ & $57 \%$ & $13 \%$ & - & $30 \%$ \\
\hline 1 & $57 \%$ & $10 \%$ & $33 \%$ & $52 \%$ & $15 \%$ & - & $33 \%$ \\
\hline 2 & - & - & - & $50 \%$ & $16 \%$ & - & $34 \%$ \\
\hline 3 & - & - & - & $15 \%$ & $6 \%$ & $69 \%$ & $10 \%$ \\
\hline 4 & - & - & - & $16 \%$ & $6 \%$ & $68 \%$ & $10 \%$ \\
\hline
\end{tabular}


Table S10: Means and standard deviations of standardized predictor variables from Table 4.

\begin{tabular}{lrr}
\hline Variable & Mean & SD \\
\hline AOD & 0.06 & 0.10 \\
monthly active fire $250 \mathrm{~km}$ (number of) & 253 & 637 \\
monthly active fire $100 \mathrm{~km}$ & 50 & 128 \\
monthly active fire $50 \mathrm{~km}$ & 13 & 30 \\
monthly burnt area $250 \mathrm{~km}$ & 94 & 529 \\
monthly burnt area $50 \mathrm{~km}$ & 3 & 26 \\
monthly burnt area $10 \mathrm{~km}$ & 0.1 & 0.7 \\
monthly mean rainfall $(\mathrm{mm})$ & 74 & 46 \\
monthly mean wind speed $(\mathrm{km} / \mathrm{h})$ & 5 & 3 \\
season mean daily max temp $\left({ }^{\circ} \mathrm{C}\right)$ & 22 & 5 \\
industrial 300m $(\%)$ & 7 & 19 \\
\hline
\end{tabular}

Table S11: Results of cross-validation for Model 4 for each region.

\begin{tabular}{lrrrrrrrr}
\hline Region & $\begin{array}{r}\text { Number } \\
\text { of } \\
\text { sites }\end{array}$ & $\mathrm{n}$ & $\mathrm{R}^{2}$ & $\mathrm{R}^{2} \mathrm{CV} \mathrm{R}^{2}$ & $\mathrm{CV} \mathrm{R}$ & $\mathrm{RMSE}$ & $\mathrm{CV}$ RMSE \\
& 75 & 23,472 & $55 \%$ & $51 \%$ & $46 \%$ & 0.68 & 6 & 6 \\
\hline Australia & 26 & 10,091 & $75 \%$ & $72 \%$ & $65 \%$ & 0.81 & 4 & 5 \\
NSW & 18 & 4,692 & $67 \%$ & $58 \%$ & $48 \%$ & 0.70 & 5 & 6 \\
QLD & 11 & 3,825 & $78 \%$ & $73 \%$ & $62 \%$ & 0.79 & 4 & 5 \\
VIC & 9 & 2,515 & $85 \%$ & $78 \%$ & $57 \%$ & 0.76 & 3 & 7 \\
SA & 6 & 1,165 & $74 \%$ & $59 \%$ & $29 \%$ & 0.54 & 4 & 3 \\
WA & 2 & 611 & $90 \%$ & $67 \%$ & $25 \%$ & 0.50 & 3 & 6 \\
ACT & 2 & 496 & $78 \%$ & $51 \%$ & $20 \%$ & 0.45 & 3 & 6 \\
TAS & 2 & & & & & & \\
\hline
\end{tabular}

$\mathrm{R}^{2}=$ pseudo- $\mathrm{R}^{2} \quad \mathrm{R}_{\mathrm{m}}^{2}=$ marginal $\mathrm{R}^{2} \quad \mathrm{R}_{\mathrm{c}}^{2}=$ conditional $\mathrm{R}^{2} \quad$ CV RMSE = RMSE from LOOCV

$\mathrm{CV} \mathrm{R}=$ Pearson correlation from LOOCV CV $\mathrm{R}^{2}=\mathrm{R}^{2}$ from LOOCV 


\section{Highlights}

- Accounting for temporal variation is critical to model fit.

- The model was very sensitive to high-concentration air pollution events.

- Satellite-based AOD and other predictor variables did not substantially improve model performance.

- Model performance varied considerably between states and regional models were necessary.

- Mixed effects models that use pseudo $\mathrm{R}^{2}$ values overstate the proportion of variation explained by the model. 